\title{
The Correlation between Residential Density and Greenhouse Gas Emissions in Surabaya City
}

\author{
Submitted: 19 March 2014 \\ Accepted: 30 June 2014 \\ Rulli Pratiwi Setiawan', Ema Umilia ${ }^{2}$, Ketut Dewi Martha Erli Handayeni ${ }^{3}$ \\ ${ }^{1,2,3}$ Sepuluh Nopember Institute of Technology, Surabaya, Indonesia \\ rulli.setiawan@urplan.its.ac.id
}

\begin{abstract}
Population growth is happening in cities, including Surabaya as the second largest metropolitan region in Indonesia. The population growth has an impact to the residential density, whereas residential is usually the largest part of land use in urban areas. In Surabaya, residential use covers more than $60 \%$ of the total area. The intensive use of residential area has impacts on the environment. One significant issue is the consumption of energy that produces greenhouse gas emissions. This study is aimed at explaining the relationships between residential density and greenhouse gas emissions in Surabaya City, Indonesia. The residential density will be divided into three categories, i.e. low, medium and high density. The category of density is taken from the Identification Report of Surabaya Spatial Plan. The results of this study indicate that there are significant differences in the electrical energy consumption for the household sector in each residential density. These differences are mainly influenced by variables such as car ownership, ventilation system, the use of electrical power, cooking fuel and the way to use the home appliances. The highest total energy consumption per month exists in high density type. Although the average smallest energy consumption per household exists in medium density, the total energy consumption in medium density is much greater than that in the low density because the number of households in medium density is greater. The final result shows that the correlation between the total production of GHG emissions (CO2) and density has a direct or positive relationship, which means that the greater the density, the higher the production rate of GHG emissions (CO2).
\end{abstract}

Keywords: correlation, greenhouse gas emissions, land use, residential density, settlements, urban

\section{Introduction}

Urban area is mostly characterized by the highest share of settlement use. The share is generally more than $50 \%$ of the area. This case also happened in Surabaya City, whereas the settlement use covers more than $60 \%$ of the total area. The settlements in Surabaya have a diverse range of density, from low density to high density. Each type of density has different characteristics that are mainly based on the community who live in.

The city shape is an important element in the city planning process. A better understanding of the relationship among urban structure, energy and environment is crucial in the formulation of strategies that can be applied to solve the environmental problems (Anderson, 1996). Cities are responsible for the highest share of greenhouse gas emissions at a global level (Hoornweg et al., 2011). Cities are estimated produce up to $80 \%$ of the total emissions (United Nations, 2007). On the other hand, they also offer the greatest mitigation possibilities.

Residential density associated with the development of the city in particular became a major issue in the analysis of environmental and energy saving measures (Norman et al., 2006). According to the studies carried out previously, housing is identified as the most significant contributor of an individual's carbon load. Particularly household energy consumption is the most significant factor contributing to carbon emissions (Heinonen and Junnila, 2011; Norman et al., 2006). Residents of cities, especially the rich, are the largest contributors to climate change and will be required to adjust their current lifestyles. On the other hand, climate change will affect most residents of cities, particularly the urban poor and vulnerable (The World Bank, 2010).

The relationship between household consumption and $\mathrm{CO}_{2}$ emissions in Danish community showed that overall growth in household consumption of energy was the main driving force behind growth in $\mathrm{CO}_{2}$ emissions (Munksgaard et al., 2000). A study on household energy consumption carried out in European Union found that household energy consumption varied with expenditure (Reinders et al., 2003). The average energy requirement of households in 11 European Union member states was analyzed and it was found that differences between countries in the total energy requirement of households are mainly due to differences in total household expenditure. 
In other developed country, there has been a study in the life-cycle analysis of energy use and greenhouse gas emissions by comparing high and low residential density in Canada (Norman et al., 2006). The results show that energy use and GHG in low density suburban development is more intensive rather than in high density urban core development.

A spatial analysis on residential greenhouse gas emissions has been carried out in Toronto (VandeWeghe and Kennedy, 2007). The result shows that the top ten in terms of GHG emission are located in the lower-density suburbs, and their high emissions were mostly caused by private auto use. Moreover, there is a correlation between socioeconomic factors such as income levels, citizen age distributions and available residential area and the varying GHG emissions across the Toronto Census Metropolitan Area.

From the previous research done in Canada, it is then important to ensure whether the phenomena similarly happen in developing country, such as Indonesia. This study aimed at explaining the correlation between residential density in low, medium and high level and greenhouse gas emissions in Surabaya City. The specific objectives are:

a. to identify the characteristics of residential in each type of density;

b. to estimate the greenhouse gas emissions produced from each type of residential density;

c. to analyze the correlation between the residential density and greenhouse gas production in the City of Surabaya.

Table 1: Comparison of Residential Density of the Selected Case Study

\begin{tabular}{clrrrc}
\hline No. & Districts & $\begin{array}{r}\text { Total Area } \\
(\mathbf{H a})\end{array}$ & $\begin{array}{r}\text { Total Population } \\
\text { (inh) }\end{array}$ & $\begin{array}{r}\text { Density } \\
\text { (inh/Ha) }\end{array}$ & $\begin{array}{c}\text { Classification of } \\
\text { Density }\end{array}$ \\
\hline 1. & Tegalsari & 429,38 & 119.471 & 278,24 & High \\
2. & Genteng & 404,75 & 69.691 & 172,18 & Medium \\
3. & Jambangan & 418,62 & 42.961 & 102,63 & Low \\
\hline
\end{tabular}

Source: Adapted from Identification Report of Surabaya Spatial Plan, 2009

\section{Approach}

\subsection{Determination of Residential Density and Case Study Area}

Density in the residential area in Surabaya varies from low to high density. The density in city core is relatively higher than in the city edge. The density explained in this study is gross density, as the data of net density is not available and hard to get.

Based on the Identification Report of Surabaya Spatial Plan (Surabaya City Government, 2009), the density in Surabaya is divided into three categories, i.e.:

a. $>250$ inhabitants/Ha: high density

b. $150-250$ inhabitants/Ha: medium density

c. $<150$ inhabitants/Ha: low density

The unit analysis in this study is district. AS Surabaya City has 33 districts, so each type of residential density is through a case study. The factor considered in choosing the study area is the total area. Out of 33 districts in Surabaya, there is only one type of total area that exists in all classification of residential density, i.e. the total area of ca. $400 \mathrm{Ha}$. This total area is found in Tegalsari District that corresponds to high residential density, Genteng District that corresponds to medium density, and Jambangan District that corresponds to low density.

\subsection{Correlation of Residential Density and GHG Emissions}

Calculation on the greenhouse gas emissions produced in Surabaya City is done by divided the GHG emissions into 2 parts, i.e. direct and indirect emissions. The direct emissions consist of the consumption of vehicle fuel and cooking fuel, whereas the indirect emissions consist of consumption of electricity. The direct emissions are also known as primary emissions, while the indirect emissions are known as secondary emissions.

The next step to calculate the greenhouse gas emissions is classifying the GHG emissions based on the source and converting the emissions into $\mathrm{CO}_{2}$ value.

Correlation of residential density and GHG emissions was analyzed using bivariate correlation in SPSS 16. The bivariate correlation can indicate the degree and direction of relationship. In this case, Pearson's correlation coefficient was used as a measure of linear association.

\section{Results and Discussion}

\subsection{Characteristics of Energy Consumption in Each Residential Density}

The result of the cross tabulation analysis showed that the household energy consumption is significantly different in each residential density based on the number of car ownerships, ventilation systems, electricity power usage, cooking fuel usage and the way to use the electricity. Comparisons of electricity use and the way to use electricity in each residential density are shown in Figure 1 and 2. 


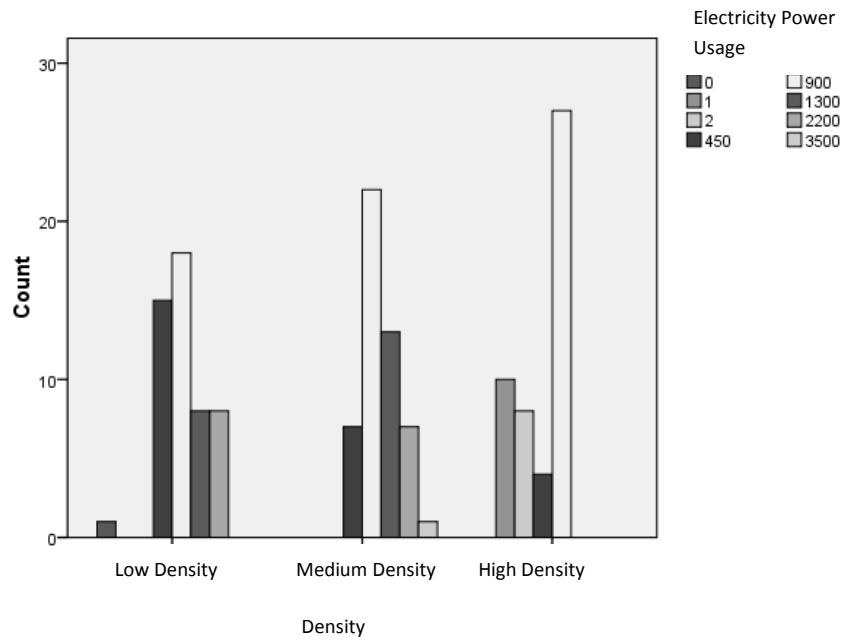

Figure 1. Comparison on Electricity Power Use in Each Residential Density

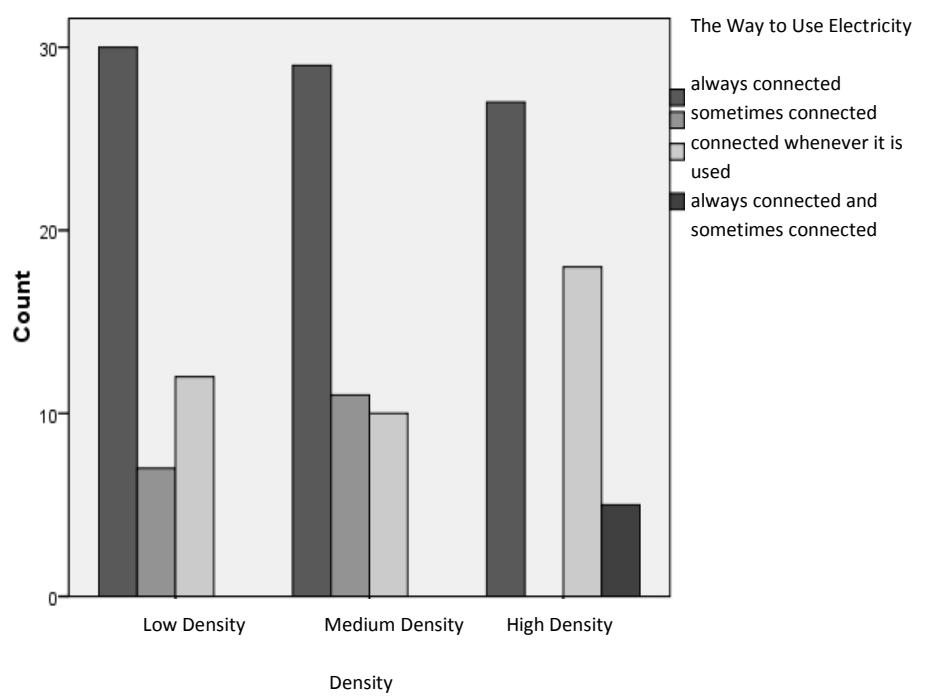

Figure 2. Comparison on the Way to Use Electricity in Each Residential Density

\subsection{GHG Emissions Produced in Residential Density}

In particular, estimating the production of GHG emissions associated with the residential required the amount of energy consumption in the household sector. In this study, energy consumption was calculated from the electricity use, vehicle fuel and cooking fuel. The steps on calculating the production of GHG are described as follows:

a. Calculate the average consumption per household unit in the selected area.

b. Calculate the total energy consumption by multiplying the number of households in the selected areas with the average energy consumption.

c. Calculate the production of $\mathrm{GHG}$ emissions $\left(\mathrm{CO}_{2}\right)$ by multiplying the total energy consumption and the emission factors. In this study, emission factor for electricity referred to the Energy and Mineral Resources Minister Letter no. 3783/21/600.5/2008. The factor is $0.89 \mathrm{~kg} / \mathrm{kWh}$.

According to the table 2 and figure 3 , it can be concluded that the highest average energy consumption per household per month existed in high density residential area, except for the cooking fuel use. In the low density residential area, the proportion of household that use cooking fuel in the form of kerosene is much lower than the household that use LPG. Whereas, the lowest average energy consumption existed in medium residential density. The results also indicate that there is a correlation between socio-economic character and the energy consumption. Figure 3 also shows that the average energy consumption per household unit in each residential density is not different significantly. 
Table 2: Average Household Energy Consumption per Month based on Residential Density

\begin{tabular}{llrrrr}
\hline No. & Density Type & \multicolumn{4}{c}{ Average Energy Consumption } \\
\cline { 3 - 6 } & & $\begin{array}{c}\text { Electricity } \\
\text { (kWh) }\end{array}$ & $\begin{array}{c}\text { Vehicle Fuel } \\
\text { (Litre) }\end{array}$ & $\begin{array}{c}\text { Cooking Fuel LPG } \\
\text { (Kg) }\end{array}$ & $\begin{array}{c}\text { Cooking Fuel } \\
\text { Kerosene (Litre) }\end{array}$ \\
\hline 1. & High Density & 267.63 & 49.98 & 11.20 & 10.00 \\
2. & Medium Density & 235.25 & 46.38 & 10.30 & 14.00 \\
3. & Low Density & 239.57 & 52.51 & 10.69 & 13.00 \\
\hline
\end{tabular}

Table 3: Total Household Energy Consumption per Month based on Residential Density

\begin{tabular}{|c|c|c|c|c|c|c|}
\hline \multirow[t]{2}{*}{ No. } & \multirow[t]{2}{*}{ Density Type } & \multirow{2}{*}{$\begin{array}{l}\text { Number of } \\
\text { Households }\end{array}$} & \multicolumn{4}{|c|}{ Total Energy Consumption } \\
\hline & & & $\begin{array}{l}\text { Electricity } \\
\text { (kWh) }\end{array}$ & $\begin{array}{l}\text { Fuel Vehicle - } \\
\text { Gasoline (TJ) }\end{array}$ & $\begin{array}{l}\text { Cooking Fuel - } \\
\text { LPG (TJ) }\end{array}$ & $\begin{array}{l}\text { Cooking } \\
\text { Fuel - } \\
\text { Kerosene } \\
\text { (TJ) }\end{array}$ \\
\hline 1. & High Density & 29.868 & $7.993 .432,79$ & $53.172 .347,16$ & $16.727 .468,84$ & $432.875,24$ \\
\hline 2. & Medium Density & 17.423 & $4.098 .701,94$ & 28.783.394,12 & $8.788 .184,26$ & $530.269,00$ \\
\hline
\end{tabular}

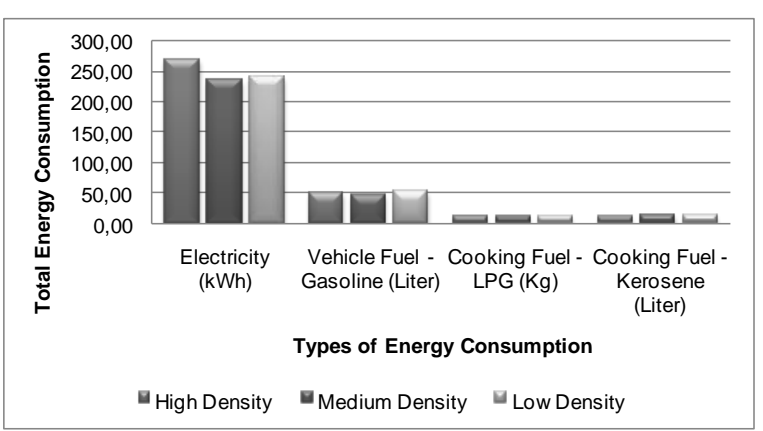

Figure 3. Average Household Energy Consumption per Month based on Residential Density

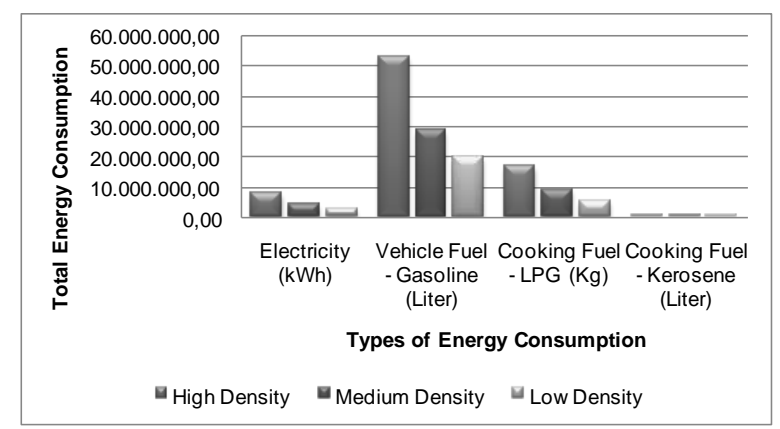

Figure 4. Total Household Energy Consumption per Month based on Residential Density

According to the table 3 and figure 4, it can be concluded that the highest energy consumption for all types of energy existed in high residential density, whereas the lowest energy consumption existed in low residential density. Although the lowest average household energy consumption existed in medium residential density, the total energy consumption in medium density is higher than that in low residential density due to the number of households. Figure 4 also shows that there is significance difference of the total energy consumption in each residential density. As a result, the level of greenhouse gas emissions $\left(\mathrm{CO}_{2}\right)$ in each residential density is also different, as shown in the table 4. It also shows that the highest total production of GHG emissions existed in high residential density due to the total of energy consumption. In reverse, the lowest total production of GHG emissions existed in low residential density

Table 4: Total GHG Emissions based on Residential Density in Household Sector

\begin{tabular}{|c|c|c|c|c|c|c|}
\hline \multirow[t]{2}{*}{ No. } & \multirow[t]{2}{*}{ Density Type } & \multicolumn{4}{|c|}{$\mathrm{CO}_{2}$ Emissions $(\mathrm{Kg})$} & \multirow{2}{*}{$\begin{array}{c}\text { Total } \\
\text { Emissions } \\
\mathrm{CO}_{2}(\mathrm{Kg})\end{array}$} \\
\hline & & Electricity & $\begin{array}{c}\text { Fuel Vehicle - } \\
\text { Gasoline }\end{array}$ & $\begin{array}{c}\text { Cooking Fuel - } \\
\text { LPG }\end{array}$ & $\begin{array}{c}\text { Cooking Fuel - } \\
\text { Kerosene }\end{array}$ & \\
\hline 1. & High Density & $8,547 \mathrm{E}+07$ & $4,422 \mathrm{E}+13$ & $1,267 \mathrm{E}+13$ & $3,735 \mathrm{E}+11$ & $5,726 \mathrm{E}+13$ \\
\hline 2. & Medium Density & $4,382 \mathrm{E}+07$ & $2,394 \mathrm{E}+13$ & $6,654 \mathrm{E}+12$ & $4,575 \mathrm{E}+11$ & $3,105 E+13$ \\
\hline
\end{tabular}




\subsection{Correlation between Residential Density and GHG Emissions}

Correlation between residential density and GHG emissions is determined through bivariate correlation (two variables) that can indicate the level/degree and direction of relationship. Then, a model of correlation between the GHG emissions and residential density in each type can be generated. The result is shown in the table below.

Table 5: Bivariate Correlation Model between Residential Density and GHG Emissions in Surabaya

\begin{tabular}{|c|c|c|}
\hline No. & Variable & Test Score \\
\hline 1. & $\begin{array}{l}\text { Pearson Correlation: } \\
\text { Total Production of GHG and Level of Density }\end{array}$ & 0,991 \\
\hline $\begin{array}{l}2 . \\
3 .\end{array}$ & $\begin{array}{l}\text { Significance (2-tailed) } \\
\text { Number of sample }\end{array}$ & $\begin{array}{c}0,087 \\
3\end{array}$ \\
\hline
\end{tabular}

According to the table 5 , it can be seen that the value of significance (two-tailed test) is less than 0.100 , which means that the correlation between the type of residential density and the total GHG emissions $\left(\mathrm{CO}_{2}\right)$ is considered to be significant, at the $90 \%$ level of confidence. The degree of correlation of the two variables is very strong because the Pearson correlation value is almost close to 1, i.e. 0.991 . The value of Pearson Correlation shows positive value, which means that the higher the density, the higher the production rate of $\mathrm{CO}_{2}$ emissions.

The correlation analysis between residential density and energy consumption show a unique result, i.e. the higher the residential density, the less consumption of vehicle fuel.

\section{Conclusion}

The study was carried out based on primary survey held in some case study areas, i.e. residential areas with low, medium and high density. The results obtained from the study are explained as follows:

(1) The household energy consumption is significantly different in each residential density based on the number of car ownerships, ventilation systems, electricity power usage, cooking fuel usage and the way to use the electricity.

(2) The interesting finding of this result is related to the habit of electricity usage or home appliances usage. Residents in high residential density are used to plug out the cable whenever it is not used. Residents in low residential density always plug in the cable all the times.

(3) The highest average energy consumption per household per month existed in high density residential area, except for the kerosene cooking fuel use. The lowest average energy consumption existed in medium residential density due to the socio-economic characteristics. The average energy consumption per household unit in each residential density is not different significantly.

(4) The highest energy consumption for all types of energy existed in high residential density, whereas the lowest energy consumption existed in low residential density. Although the lowest average household energy consumption existed in medium residential density, the total energy consumption in medium density is higher than that in low residential density due to the number of households. The total energy consumption in each residential density is different significantly.

(5) There is a significant correlation between the total productions of $\mathrm{GHG}$ emissions $\left(\mathrm{CO}_{2}\right)$ with 90 percent level of confidence.

(6) The degree of correlation is very strong because the Pearson correlation value is close to 1, i.e. 0.991.

(7) The correlation between the residential density and the total GHG emissions production has a positive correlation, which means, the higher the density, the higher the higher the production rate of $\mathrm{CO}_{2}$ emissions.

Based on the results obtained, there are several recommendations:

(1) Attributes of income and expenditure are not significantly different in each type of residential density, because the residential density in this study is observed based on the population density, not based on the residential types. Therefore, the attributes of income and expenditure cannot be directly related. Moreover, the sampling technique also used random sampling. It does not classify the sampling based on residential types.

(2) Further study on the habits of energy consumption in each residential density is required to support the assumption that the higher the density, the higher probability of energy efficiency in the household sector.

(3) It is required to control the residential density in order to interfere the production of $\mathrm{CO}_{2}$ emissions. Controlling the density is related to the control of household numbers that can significantly affect the level of density in the city.

(4) Community has a significant role in the energy use. Therefore, the community should be encouraged to use the energy wisely.

(5) Promoting energy efficient home appliances is recommended for all communities. 


\section{Acknowledgements}

The authors are grateful to the Directorate for Higher Education, Ministry of National Education, Republic of Indonesia for providing funding for this research through Hibah Penelitian Laboratorium Project No. 1027.109/IT2.7/PN.01/2012. This arcticle has been presented at the International Conference of Regional Development on 20-21 November 2013 (ICRD 2013) in Semarang, Indonesia.

\section{References}

Anderson, W., 1996. Urban Form, Energy and the Environment: A Review of Issues, Evidence and Policy. Urban Studies 33, 7-36.

Heinonen, J., Junnila, S., 2011. Case study on the carbon consumption of two metropolitan cities. Int J Life Cycle Assess 16, 569-579.

Hoornweg, D., Sugar, L., Gomez, C.L.T., 2011. Cities and greenhouse gas emissions: moving forward. Environment and Urbanization.

Munksgaard, J., Pedersen, K.A., Wien, M., 2000. Impact of household consumption on CO2 emissions. Energy Economics 22, 423-440.

Norman, J., MacLean, H.L., Kennedy, C.A., 2006. Comparing High and Low Residential Density: LifeCycle Analysis of Energy Use and Greenhouse Gas Emissions. Journal of Urban Planning and Development 132, 10-21.

Reinders, A.H.M.E., Vringer, K., Blok, K., 2003. The direct and indirect energy requirement of households in the European Union. Energy Policy 31, 139-153.

Surabaya City Government, 2009. Identification Report of Surabaya Spatial Plan 2009.

The World Bank, 2010. Cities and Climate Change: an Urgent Agenda, Urban Development Series. The World Bank, Washington DC.

United Nations, 2007. City planning will determine pace of global warming [WWW Document]. URL http://www.un.org/News/Press/docs/2007/gaef3190.doc.htm (accessed 11.25.12).

VandeWeghe, J.R., Kennedy, C., 2007. A Spatial Analysis of Residential Greenhouse Gas Emissions in the Toronto Census Metropolitan Area. Journal of Industrial Ecology 11, 133-144. 